\section{Geriatrics: the "sexy"}

\section{specialty}

$\mathrm{T}$ here are fewer than 200 geriatricians in Canada, but the estimated need is over 600 , a number that is expected to skyrocket as the number of people over age 65 doubles in the next 25 years. Elderly baby boomers "will just expect" complex medical needs to be met, says Dr. Laura Diachun, a geriatrician at London, Ont.'s Parkwood Hospital and associate professor and geriatric medicine program director at the University of Western Ontario.

Diachun and her Parkwood colleagues have implemented several novel approaches to stimulate interest in elder care among medical students. At Spring Galas young medical students escorted seniors to formal dances. Medical trainees have also golfed, bowled, played cards, done aerobics and socialized with seniors at Parkwood.

"We really try to make it a lively endeavour for [students] to link up with older patients," says Diachun. "Since then, we've had a ro-fold increase in the number of students doing an elective in geriatrics." Many may eventually choose family medicine or other areas of practice, but exposure to the care of older persons is invaluable.

"It needs to be clear to [medical students] that unless they go into pediatrics, they will spend $50 \%$ of their time work-

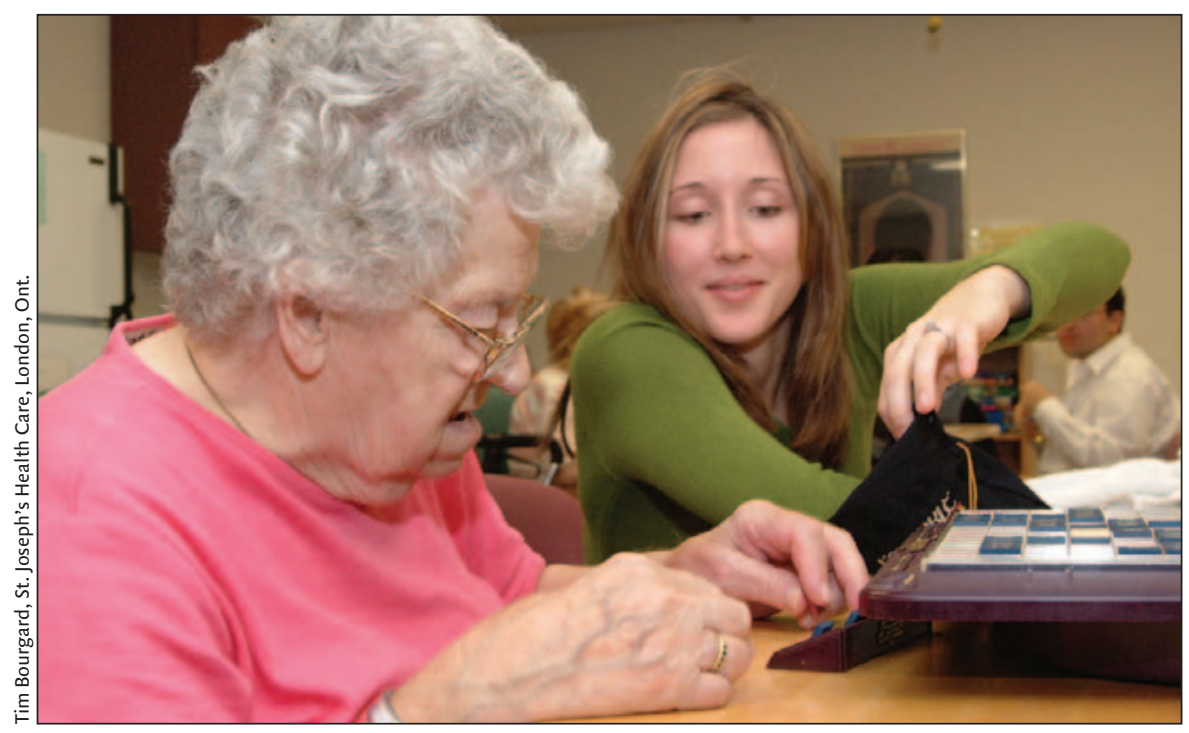

Medical students, such as Jackie Nelson, are encouraged to socialize with seniors.

ing with patients over the age of $6_{5}$," says Diachun. "We have to show what's fantastic about caring for older people."

"We need to be proactive as a society," she adds.

"Geriatrics is totally sexy," insists Diachun. "It's the intellectual challenge of it. It's the chance to put all the pieces of the puzzle together for the family that's been to doctor after doctor after doctor. To put it all together, to be a detective, to be with people at their really intimate moments, to really make a difference ... to have tremendous job satisfaction. I think those are the things that make it sexy."

Diachun recently coauthored Improving Recruitment into Geriatric Medicine in Canada (J Am Geriatr Soc 2006;54: I453-62). The report contains 6 recommendations, including considering feedback from both the "converted" (i.e., geriatric medicine trainees and geriatricians) and "not-yet converted" (residents and medical students); implementing and integrating local, provincial and national mentorship programs; implementing advocacy, recruitment and incentive campaigns to increase attractiveness of geriatric medicine as a career choice; decreasing duration of geriatric medicine training and increasing training opportunities in geriatric medicine to international medical graduates. - Lynne Swanson, London, Ont.

DOI:I0.1503/cmaj.o6r7I7 
medically appropriate," in that the patient may be able to meet the minimum goal, but their chances are poor and "there will be significant negative medical effects on the patient, including, but not limited to, pain and suffering."

If, after determining treatment is not medically indicated, a patient or family may ask that treatment continue and the physician would be asked to get a second opinion. If that second opinion indicates medical treatment is indicated, the original physician would have to continue treating the patient, or find another physician who will provide that care.

The guidelines also recommend patients or their families be given at least 4 days' notice prior to any final decision to withdraw medical treatment. Patients and their families are, at all times, entitled to seek out a physician who will provide care.

"The college is making every effort to be thoughtful in this process and see everyone's point of view," says Babick. "But at the end of the day, there needs to be a process that everyone can work with. And we have to remember, these are decisions where often there is no right answer." — Dan Lett, Winnipeg

DOI:Io.I503/cmaj.I6I7I5

\section{Polio eradication}

\section{setback in India}

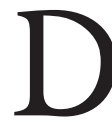
espite a nearly Io-fold surge in the incidence of polio in India over the past 2 years, researchers are optimistic it can be eliminated in that country by 2008 .

In 2006, India had 597 reported polio cases (as of Dec. I8), up from 66 the year before, which was the lowest recorded rate ever, says Sona Bari, spokesperson for the Polio Eradication Initiative at the World Health Organization.

The increase in polio cases may be due to a decrease in the vaccine coverage. In 2005, 93\% households were vaccinated in India's campaign against polio, but in January 2006, the coverage was $89 \%$. T. Jacob John, a member of India Expert Advisory Group, a group of polio eradication experts, says "virtually $100 \%$ coverage is necessary not simply with 3 but some io or even more [doses] in places with very high force of wild virus transmission."

India deploys 2 types of vaccines in its battle against polio: the standard trivalent vaccine, which works against all 3 strains of poliovirus; and, since 2005 , a monovalent vaccine for specific protection against the most prevalent type I poliovirus. However, despite the use of monovalent vaccine since 2005, the number of cases has not decreased. Of the 597 reported cases last year, I8 were type 3 and the rest were type I.

Nicholas Grassly, a researcher at the Imperial College, London, UK, says "It appears that this unfortunate increase [in polio cases] resulted from an increase in mid-2005 of the number of houses 'missed' by the pulse polio program in western Uttar Pradesh."

Missed houses include those where the children were absent, vaccination was refused or it was reported that the child had received vaccine despite evidence to the contrary.

India's 2006 campaign emphasized logistics, according to Bari, including meticulous plans, thorough training of vaccinators, availability of vaccine and funds, deployment of necessary supervisory personnel and a full information campaign throughout the community.

Despite the surge in cases, the strategy seems to be succeeding. "The [pulse polio] program has seen significant improvements over [2005], and the number of missed houses is at an all time low," says Grassly.

He adds that the major challenge now is to ensure that children receive the new monovalent vaccine early enough in their life, which requires frequent vaccination rounds, and that missed children don't remain missed. "If this can be achieved, then we should not see polio in India after 2008," he comments.

While vaccination is vital, there are also systemic factors potentially feeding the prevalence rate of the virus. Grassly and coworkers recently studied 96 42I polio-affected Indian children, which suggests that high population density and poor sanitation are key factors for the transmission of poliovirus in Uttar Pradesh and Bihar, the states

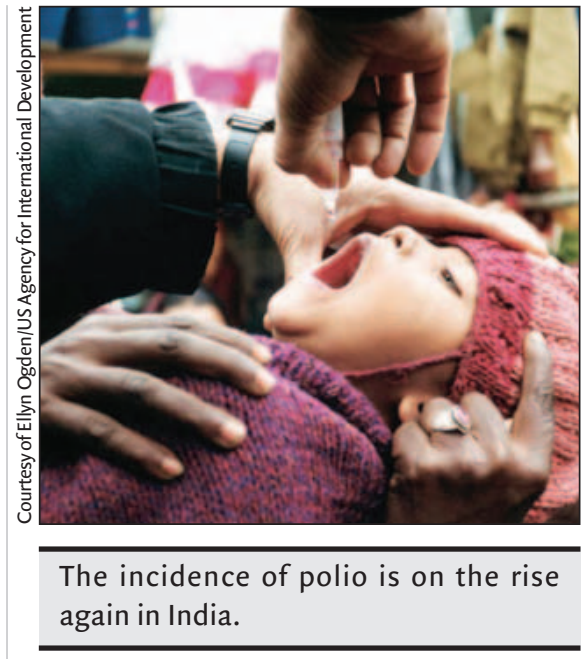

that have accounted for most of the polio cases in India over the last few years (Science 2006;3I4:II50-3).

These same factors facilitate the transmission of other infectious diseases that interfere with the efficacy of the oral polio vaccine, says Grassly. "New strategies based on the use of monovalent vaccine, which is more efficacious, have the potential to now finish the job and eradicate polio from India." - Dr. Sanjit Bagchi, West Bengal, India

DOI:I0.1503/cmaj.o6r7I6

\section{Global Fund pulls grants from}

\section{mismanaging countries}

$\mathrm{D}$ ue to the mismanagement and theft of earlier grants, the Global Fund to Fight Malaria, Tuberculosis and HIV/AIDS (GF) has rejected grant applications from a number of African countries, including some that are among the worst hit by HIV/AIDS.

Affected countries, including Kenya, Uganda, Togo, Zimbabwe, Namibia and Tanzania, say the grant freeze will badly affect their HIV/AIDS control programs. Since its inception in 200I, the GF has helped provide antiretroviral treatment to 600000 HIV/AIDS patients; the new financing over 5 years will support about 200000 .

The GF, a partnership among governments, civil society, the private sector and affected communities to support 